\title{
Study of Psychiatric Comorbidity in the Survivors of Deliberate Self Harm ina Rural Setting
}

\author{
Sreelatha P,Shailaja B, Sushma V Inamdar, Gopalakrishnan G, \\ Department of Psychiatry, M.V.J Medical College \& Research Hospital (MVJ MC \& RH), Hoskote, Bangalore
}

\begin{abstract}
:
Background: Deliberate self-harm (DSH) is one of the most common causes of morbidity and mortality throughout the world, psychiatric comorbidity in such patients further worsens the picture.

Scanty data are available from India, much less on the correlation between the psychiatric morbidity and the intent of the act.

Aims And Objectives: To categorize the survivors of the DSH on the degree of intentionality of the act.

To study the correlation of the characteristics of the suicidal act and the psychiatric comorbidity with the intentionality of the act.

Methodology: In this cross-sectional study, 90 patients referred for consultation-liaison psychiatric services with the history of deliberate self-harm over the study period of 1 year were assessed using Beck's Suicidal Intent Scale and ICD 10 Mental and Behavioural Disorders. Results were analyzed using SPSS version 16 and Pearson's Chi-Square test.

Results: $95.5 \%$ of the low and 66.7\% moderate intent patients had impulsive attempt whereas $80 \%$ of the high intent patients had planned attempt. Interpersonal problem with the person other than the spouse acted as precipitant in $52.5 \%$ of low and $33.5 \%$ of moderate intent patients, in $40 \%$ of the patients with high intent psychopathology itself was precipitant. Only $1.5 \%$ of low and $16.7 \%$ of moderate intent patients wanted to die, whereas $40 \%$ of high intent patients expected death as an outcome. No psychiatric diagnosis $(n=26 ; 38.8 \%)$ followed by adjustment disorder $(n=19 ; 28.4 \%)$ substance dependence $(n=11 ; 16.4 \%)$ were found to be more among the low intent patients, moderate depressive disorder without somatic syndrome ( $n=7 ; 38.9 \%)$ followed by adjustment disorder $(n=5 ; 27.8 \%)$ schizophrenia and other psychosis $(n=3 ; 16.7 \%)$ were more among moderate intent patients, obsessive compulsive disorder with predominantly obsessions $(n=2 ; 40 \%)$ severe depression without psychotic symptoms $(n=2 ; 40 \%)$ were found more among high intent patients.

Conclusion: Characteristics of the suicidal act in terms of preparation behind the act, precipitant, motive behind the act and the psychiatric comorbidity vary significantly with the degree of intentionality of the act.
\end{abstract}

\section{Introduction}

Some of those who attempt self-harm and survive do it with the strong intent to die but many do not. Presently, no distinctive nomenclature exists for these two groups ${ }^{[1,2]}$.

Various terms like 'attempted suicide', deliberate self-poisoning', 'deliberate self-injury' and 'parsuicide' have been used interchangeably. The most accepted term in recent time to describe such behavior is deliberate selfharm ${ }^{[3]}$.

WHO defines deliberate self-harm (DSH) as 'an act with non-fatal outcome in which an individual deliberately initiates a non-habitual behavior, that without intervention from others will cause self-harm, or deliberately ingests a substance in excess of the prescribed or generally recognized therapeutic dosage, and which is aimed at realizing changes that the person desires via the actual or expected physical consequences, ${ }^{[4]}$. As in many countries, DSH in India is an unrecognized, hidden and silent epidemic ${ }^{[3]}$. It is one of the top five causes of acute medical admissions for both males and females ${ }^{[3]}$.

DSH occurs for diverse reasons, one important factor being psychiatric disorder. Several studies of DSH across the countries have reported high rates of psychiatric disorder which resemble those found in suicides ${ }^{[5]}$. The importance of comorbidity in suicidal behavior is apparent from the study by Foster et al in which it increased the risk of suicide by six fold compared with the risk in individuals with psychiatric disorders alone ${ }^{[6]}$.

Though many studies in the past have revealed the association between the psychiatric comorbidity and the DSH, there were less attempts to study correlation the characteristics of the act and the psychiatric comorbidity with the degree of intent of the act.

With this background, the aim of our study is,

- To categorize the survivors of the DSH on the degree of intent of the act.

- To study the correlation of characteristics of the act and the psychiatric comorbidity with the intent of the act. 


\section{Methodology}

This was a cross-sectional study done at MVJ MC\&RH and the study universe included 90 patients referred for consultation-liaison psychiatric services from other departments once they were medically fit. The data was collected during the study period of 12 months from July 2012 to June 2013 prospectively. The study was cleared by the institutional ethical committee and all the patients who consented toparticipate were included in the study. A semi-structured proforma was used which included socio-demographic profile and the inquiry into the suicidal act. Intent of the suicidal act was assessed by Beck's Suicidal Intent Scale ${ }^{[7]}$. This suicide intent scale was developed by Aaron T. Beck and his colleagues at the University of Pennsylvania for use with patients who attempt suicide but survive.Complete scale is a 15-item survey of two parts: Items 1 to 8 cover objective circumstances of the attempt (e.g., isolation, precautions against discovery, suicide note); Items 9 to15 reports intentions and expectations regarding the attempt.Each item scores 0-2, giving a total score range of 0-30.A score of 0-10 implies low intent, 11-20 moderate and 20-30 high. ICD 10 Classification of Mental and Behavioural Disorders was used to diagnose the psychiatric comorbidity. Initial assessment and diagnosis done by trainee psychiatrist was confirmed after a final evaluation by a senior psychiatrist. Results were analyzed using SPSS version 16 and Pearson's chi square test.

\section{Results}

Of 90 patients, 51(56.6\%) were women. The mean age was $26.97+10.6$ years (range: $15-80$ years). Majority of the acts $(n=78 ; 86 \%)$ were impulsive. Poisoning $(n=52 ; 57.8 \%)$ followed by drug overdose $(n=31$; $34.4 \%$ ) were the commonest chosen modality.

Ten patients had one suicidal attempt in the past and 2 patients had more than one attempt of which 4 previous attempts being the maximum. One of them had a family history of psychosis, 3 of them had family history of suicide. IP conflicts with the person other than spouse $(n=42 ; 46.7 \%)$ was found to be the most common precipitating factor.

More than one motive followed by the desire to change the behaviour of others were most common motives behind the act.

On categorizing the patients on the degree of intent of the act, 67 (74.4\%) patients fell under low, 18 (20\%) under moderate and $5(5.6 \%)$ under high degree of intentionality.

Mean age of the low, moderate and high intent patients was 25.67, 31.83, 26.80 years respectively.

Majority of the low intent patients were females and majority of high intent patients were males.

Poisoning was the most commonly opted method irrespective of the intent.

Majority of the patients with low intent had impulsive attempt $(n=64,95.5 \%)$ and majority of patients with high intent had planned attempt $(n=4,80 \%)$ [Pearson Chi-Square $=27.970 ; p<0.01$ ]

Majority of low intent $(52.2 \%)$ and moderate intent $(33.3 \%)$ patients had interpersonal problem with the person other than the spouse as precipitant for the suicidal act.In $40 \%$ of high intent patients psychopathology acted as the precipitating factor for the suicidal act. [Pearson Chi-Square $=26.114 ; \mathrm{p}<0.01$ ]

Only $1.5 \%$ of low and $16.7 \%$ of moderate intent patients wanted to die, whereas $40 \%$ of high intent patients expected death as final outcome [Pearson Chi-Square $=18.825 ; \mathrm{p}=0.004]$.

No psychiatric diagnosis $(n=26 ; 38.8 \%)$ followed by adjustment disorder $(n=19 ; 28.4 \%)$ substance dependence $(n=11 ; 16.4 \%)$ were found to be more among the low intent patients, moderate depressive disorder without somatic syndrome $(n=7 ; 38.9 \%)$ followed by adjustment disorder $(n=5 ; 27.8 \%)$ schizophrenia and other psychosis $(n=3 ; 16.7 \%)$ were more among moderate intent patients, obsessive compulsive disorder with predominantly obsessions $(n=2 ; 40 \%)$ severe depression without psychotic symptoms $(n=2 ; 40 \%)$ were found more among high intent patients. [Pearson Chi-Square $=96.44 ; \mathrm{p}<0.01$ ].

\begin{tabular}{|c|c|c|c|c|}
\hline \multirow[t]{2}{*}{ VARIABLES } & \multicolumn{3}{|c|}{ DEGREE OF INTENTIONALITY } & \multirow[t]{2}{*}{ TOTAL } \\
\hline & LOW & MODERATE & HIGH & \\
\hline & $(\mathrm{N}=67)$ & $(\mathrm{N}=18)$ & $(\mathrm{N}=5)$ & $(\mathrm{N}=90)$ \\
\hline \multicolumn{5}{|l|}{ SEX, N (\%) } \\
\hline Male & $25(37.3)$ & $10(55.6)$ & $4(80)$ & $39(43.3)$ \\
\hline Female & $42(62.7)$ & $8(44.4)$ & $1(20)$ & $51(56.7)$ \\
\hline AGE $($ Mean \pm SD $)$ & $25.67 \pm 6.9$ & $31.83 \pm 18.4$ & $26.80 \pm 10.8$ & $26.97 \pm 10.6$ \\
\hline \multicolumn{5}{|c|}{ PREPARATION BEHIND THE ACT, N (\%) } \\
\hline Impulsive & $64(95.5)$ & $12(66.7)$ & $1(20)$ & $77(85.6)$ \\
\hline Planned & $3(4.5)$ & $6(33.3)$ & $4(80)$ & 13(14.4) \\
\hline \multicolumn{5}{|c|}{ METHOD CHOSEN, N (\%) } \\
\hline Poisoning & $39(58.2)$ & $10(55.6)$ & $3(60)$ & $52(57.8)$ \\
\hline Drug Overdose & $24(35.8)$ & $6(33.3)$ & $1(20)$ & $31(34.4)$ \\
\hline Others & $4(6)$ & $2(11.1)$ & $1(20)$ & $7(7.8)$ \\
\hline
\end{tabular}




\begin{tabular}{|c|c|c|c|c|}
\hline \multicolumn{5}{|l|}{ PRECIPITATING FACTOR, N $(\%)$} \\
\hline IP conflicts with the person other than spouse & $35(52.2)$ & $6(33.3)$ & $1(20)$ & $42(46.7)$ \\
\hline More than one stressor & $11(16.4)$ & $4(22.2)$ & $0(0)$ & $15(16.7)$ \\
\hline Marital discord & 12(17.9) & $1(5.6)$ & $0(0)$ & $13(14.4)$ \\
\hline Others & $9(13.4)$ & $4(22.2)$ & $2(40)$ & $15(16.7)$ \\
\hline \multicolumn{5}{|l|}{ MOTIVE BEHIND THE ACT, N (\%) } \\
\hline To change the behavior of others & $20(29.9)$ & $1(5.6)$ & $0(0)$ & $21(23.3)$ \\
\hline To escape from the situation & $14(20.9)$ & $4(22.2)$ & $1(20)$ & $19(21.1)$ \\
\hline Others/More than one motive & $32(47.8)$ & $10(55.6)$ & $2(40)$ & $44(48.9)$ \\
\hline To die & $1(1.5)$ & $3(16.7)$ & $2(40)$ & $6(6.7)$ \\
\hline \multicolumn{5}{|l|}{ PSYCHIATRIC COMORBIDITY, N (\%) } \\
\hline Mild depression without somatic syndrome & $3(4.5)$ & $1(5.6)$ & 0 & $4(4.4)$ \\
\hline Moderate depression without somatic syndrome & $5(7.5)$ & $7(38.9)$ & 0 & $12(13.3)$ \\
\hline Severe depression without somatic syndrome & 0 & 0 & $2(40)$ & $2(2.2)$ \\
\hline Schizophrenia and other psychosis & 2(3) & $3(16.7)$ & 0 & $5(5.6)$ \\
\hline OCD with predominant obsessions & 0 & 0 & $2(40)$ & $2(2.2)$ \\
\hline Dissociative disorder & $1(1.5)$ & $1(5.6)$ & 0 & $2(2.2)$ \\
\hline
\end{tabular}

\section{Discussion}

Majority of our study sample had low degree of intentionality of the act. Most of our study subjects were young (mean age 26.97 years) suggesting that they constitute the vulnerable group. This observation is identical to the previous literature from India ${ }^{[2,3,8]}$ and West ${ }^{[9]}$.Studies conducted in Western countries indicate that the increase in the suicidal rates of young people is a reflection of societies' failure to provide appropriate places or sources of social identity and attachment, since they promote inappropriate, unreal expectations of individual freedom and autonomy ${ }^{[10]}$. Poor impulse control in young may also have a role.

Our study did not reveal statistically significant association between the gender and the intentionality, female preponderance found in our studyis in keeping with some of the previous studies from India ${ }^{[2,8]}$, and also from the West ${ }^{[9]}$ which can be explained by the fact that suicidal attempt is four times more in females when compared with males.

Suicide intent scores have been shown to be related to the potential lethality of the method of selfharm ${ }^{[11,12]}$.Though we could not establish statistically significant relation between the method chosen and the intentionality, self-harm by the ingestion of organophosphorous compound was the most commonly chosen modality irrespective of the intent as our study subjects belonged to rural, agrarian background and unrestricted availability of pesticides also would be a contributor, which is in keeping with the other studies from India ${ }^{[3,8,}$ ${ }^{13,14]}$ and worldwide ${ }^{[15]}$.

Majority of low intent patients had impulsive attempt, whereas majority of high intent had planned attempt,thus our study could bring out statistically significant association between the preparation behind the attempt (planned/impulsive) and degree of intentionality.

Majority of subjects with the history of previous attempts had present attempt falling under the category of low intentionality, this observation is identical to previous literature ${ }^{[2]}$.

In majority of patients with low and moderate intent, interpersonal problem with the person other than the spouse as precipitant for the suicidal act which is in keeping with the previous literature ${ }^{[3,5]}$. In nearly half of the high intent subjects, psychopathology itself acted as a precipitant for the act.

Number of patients who wanted to die among low and moderate intent was near negligible, whereas half of the subjects with high intention wanted to die.

Majority of low intent subjects had no psychiatric comorbidity followed by adjustment disorder, substance dependence which is identical to previous studies in India ${ }^{[8]}$. Moderate depressive disorder without somatic syndrome followed by adjustment disorder and psychosis were common among moderate intent patients, obsessive compulsive disorder with predominantly obsessions and severe depression without psychotic symptoms were most seen among high intent patients. Overall, two third of the study subjects had one or the other psychiatric comorbidity which is well in keeping with the previous literature ${ }^{[5,8,16]}$.

\section{Limitations}

As our study universe was constituted by only those who were referred for consultation-liaison psychiatric services, all potential subjects may not have been included in the study. 
Though we could come across different personality traits during evaluation, we did not consider further evaluation of personality disorder.

A self-report rating scale was used to assess the degree of intent and it is often difficult to assess the true intent of suicidal behaviors, because of the fear of consequences such as admission to a psychiatric hospital, or psychological defense mechanisms, subjects sometime may deny or conceal their intention to die or may also exaggerate their intention to die in order to receive help.

\section{Conclusion}

Characteristics of the suicidal act in terms of preparation behind the act, precipitant, motive behind the act and the psychiatric comorbidity vary significantly with the degree of intent of the act.

Majority of the survivors of DSH have psychiatric comorbidity and significant number of these patients may end up with primary care doctors. There is an urgent need for staff training regarding the importance of screening of such patients for psychiatric comorbidity as to reduce the chances of future attempt and for improvement of quality of life.

BasannarDA. Failedsuicideanddeliberateselfharm:Aneedforspecificnomenclature.

IndianJPsychiatry2006;48:78-83.

[2]. Bhattacharya AK, Bhattacharjee S, Chattopadhyay S, Roy P, Kanji D, Singh OP. Deliberate self-harm: A search for distinct group of suicide. Indian J Psychol Med 2011;33:182-7.

[3]. Das PP, Grover S, Avasthi A, Chakrabarthi S, Malholtra S, Kumar S. Intentional self harm seen in psychiatric referral a tertiary care hospital, Indian J Psychiatry 2008;50:187-91.

[4]. Platt, S., Bille-Brahe, U., Kerkhof, A., et al (1992) Parasuicide in Europe: the WHO/EURO multicentre study on parasuicide. I. Introduction and preliminary analysis for 1989. ActaPsychiatricaScandinavica, 85, 97-104

[5]. Camilla Haw, Keith Hawton, Kelly Houston and Ellen Townsend. Psychiatric and personality disorders in deliberate self-harm patients, BJP 2001;178:48-54.

[6]. Foster, T., Gillespie, K. and McClelland, R., (1997). Mental disorders and suicide in northern Ireland, BJP 170, 447-452.

[7]. Roy W. Beck, Jeffrey B. Morris, Aaron T. Beck. Cross-validation of the suicidal intent scale Psychological Reports, 1974;34:445446.

[8]. P.D. Bansal et al., Determinants of deliberate self-harm. Journal of Clinical and Diagnostic Research. 2011 June, Vol-5(3): 601-604.

[9]. Kessler RC, Borges G, Walters EE. Prevalence of and risk factors for lifetime suicide attempts in the national comorbidity survey Arch Gen Psychiatry 1999;56:617 26

[10]. Eckersley, R. (2002). Cultural correlates of youth suicide. Social Science and Medicine, 55 (11).

[11]. Hamdi, E., Amin,T. \&Mattar,T. (1991) Clinical correlates of intent in attempted suicide. ActaPsychiatricaScandinavica, 83, 406411.

[12]. Haw,C.,Hawton,K.,Houston, K., et al (2003) Correlates of relative lethality and suicidal intent among deliberate self-harm patients. Suicide and Life-Threatening Behavior, 33, 353-364

[13]. LathaKS,Bhat SM, D'Souza P. Suicide attempters in a general hospital unit in India: Their socio-demographic and clinical profileemphasis on cross-cultural aspects. ActaPsychiatrScand 1996;94:26-30.

[14]. Chowdhury AN, Banerjee S, Brahma A, Biswas MK. Pesticide poisoing in non-fatal deliberate self-harm: A public health issue: Study from Sundarban delta, India. Indian J Psychiatry 2007;49:262-6.

[15]. Michael Eddleston, FlemmingKonradsen. Commentary: Time for a re-assessment of the incidence of intentional and unintentional injury in India and South East Asia. International Journal of Epidemiology 2007;36:208-211

[16]. Shailaja S Patil, Mallikarjun C Yadavannavar ,Chaukimath S P. Deliberate Self Harm and Psychiatric Co Morbidity: A Hospital BasedStudy. Asian J. Exp. Biol. Sci. VOL 2(2) 2011: 367-371. 